\title{
Correction to: Efficient electrochemical oxidation of reactive dye using a novel Ti/nanoZnO-CuO anode: electrode characterization, modeling, and operational parameters optimization
}

\author{
Nastaran Akbari ${ }^{1}$. Farideh Nabizadeh Chianeh ${ }^{1}$ Ali Arab ${ }^{1}$
}

Published online: 2 November 2021

(c) Springer Nature B.V. 2021

\section{Correction to: Journal of Applied Electrochemistry https://doi.org/10.1007/s10800-021-01634-1}

In the original publication, Fig. 3 was processed incorrectly. The correct Fig. 3 is provided in this correction.

The original article has been corrected.
The original article can be found online at https://doi.org/10.1007/ s10800-021-01634-1.

Farideh Nabizadeh Chianeh

Nabizadeh@semnan.ac.ir

1 Department of Chemistry, Semnan University, Semnan, Iran
Publisher's Note Springer Nature remains neutral with regard to jurisdictional claims in published maps and institutional affiliations. 
Fig.3 A Linear sweep voltammetry curves of Bare Ti, Ti/ nanoZnO, and $\mathrm{Ti} / \mathrm{nanoZnO}_{-}$ $\mathrm{CuO}$ electrodes in $0.1 \mathrm{~mol} \mathrm{~L}^{-1}$ $\mathrm{Na}_{2} \mathrm{SO}_{4}$ solution at scan rates of $50 \mathrm{mV} \mathrm{s}^{-1}$, B Tofel plots of $\mathrm{Ti} / \mathrm{nanoZnO}-\mathrm{CuO}$ and $\mathrm{Ti} /$ nanoZnO, C Linear sweep voltammetry curves of $\mathrm{Ti} / \mathrm{nanoZnO}$ and $\mathrm{Ti} / \mathrm{nanoZnO}-\mathrm{CuO}$ in $1 \mathrm{~g}$ $\mathrm{L}^{-1} \mathrm{NaCl}$ solution at scan rates of $50 \mathrm{mV} \mathrm{s}^{-1}$
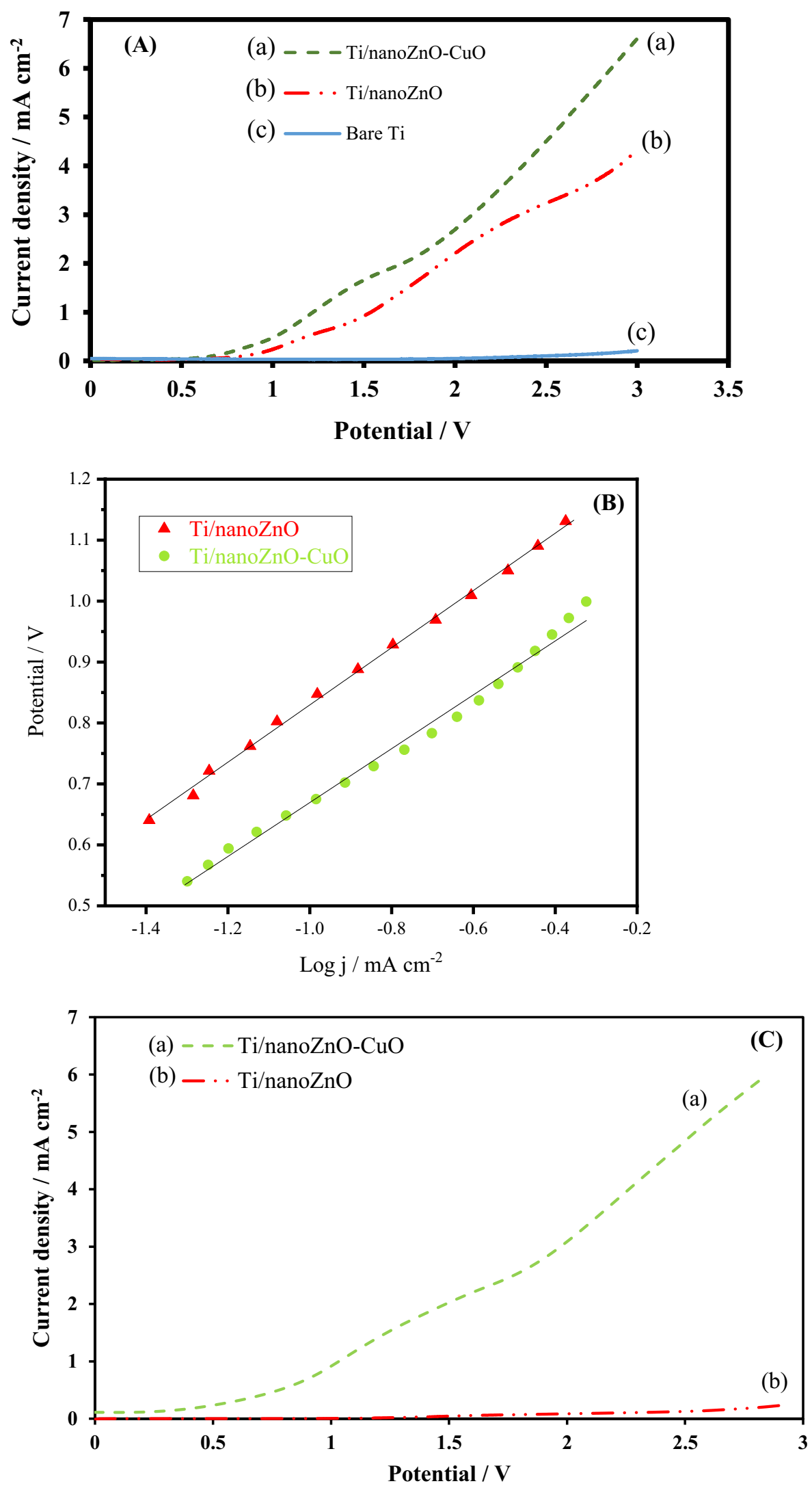